\title{
HEALTH MONITORING TESTS OF HERITAGE STRUCTURES: APPLICATION OF MEMS ACCELEROMETERS TO TWO MULTI TIER PAGODAS
}

\author{
YOHEI ENDO $^{1 *}$ AND YASUSHI NIITSU ${ }^{2}$ \\ ${ }^{1}$ Shinshu University, 4-17-1, Wakasato, Nagano City 380-8553, Japan \\ e-mail: endii@shinshu-u.ac.jp (*corresponding author) \\ ${ }^{2}$ Tokyo Denki University, 2-1200 Muzai Gakuendai Inzai, Chiba, 270-1382 Japan \\ e-mail: yniitsu@,cck.dendai.ac.jp
}

Keywords: Health monitoring test, Historical structures, MEMS accelerometers, Multi-tier pagodas

\begin{abstract}
The paper introduces a health monitoring system based on MEMS (microelectromechanical systems) accelerometers. The used MEMS accelerometers were recently developed by one of the authors. They excel in cost efficiency, calibration accuracy and robustness. The health monitoring system was installed in two multi-tiered pagodas. They were a two-tiered pagoda, Pashupatinath temple and a five-tiered pagoda, Nyatapola temple for four months. Both pagodas are located in Nepal. In both cases, a number of earthquakes were captured by the installed accelerometers, as it permitted estimation of the fundamental mode of the tested pagodas.

The paper deals with two tasks. The first task introduces the used MEMS accelerometers. The features of the accelerometers are discussed. The second task discusses the dynamic behaviour of the pagodas identified by the installed monitoring system. The paper presents adequacy of the developed MEMS accelerometers for health monitoring test of heritage structures.
\end{abstract}

\section{INTRODUCTION}

Micro-electromechanical systems (MEMS) were commonly used in the automotive and mobile technologies [1]. Recently, the MEMS are used also in the civil and structural engineering field. The MEMS permits the monitoring in the wireless environment. This is convenient especially for heritage structures since the installation of sensors can be restricted due to the access limitation in some structures. Thanks to the development in the MEMS technology, today MEMS can perform much higher resolution monitoring than decades ago [2]. However, still further investigations are necessary for reliable monitoring of historical structures by means of the MEMS. For instance, MEMS accelerometers may not capture higher modes as clearly as piezoelectric accelerometers when the structure is not sufficiently excited [3]. 
The paper discusses health monitoring tests perfected on two multi-tier pagodas in Nepal by means of MEMS accelerometers. They were a two-tiered pagoda, Pashupatinath temple and a five-tiered pagoda, Nyatapola temple for four months. During the monitoring period, the adopted systems captured a number of vibrations caused by earthquakes. This helped detecting eigenvalues and eigenvectors of the tested structures. The present research provides insights on efficient strategies for monitoring of heritage structures by means of MEMS accelerometers.

\section{DESCRIPTION OF THE DEVICE}

The developed MEMS accelerometers are composed of an acceleration sensor, microprocessing unit (MPU) board, real time clock (RTC), 1-GB flash memory and USB interface (figure $1 \mathrm{a}, \mathrm{b}$ ). The installed acceleration sensor is ADXL-355 [4]. Table 1 shows specifications. The accelerometers are tri-axial with signal-conditioned voltage outputs and 20-bit resolution digital outputs. It is possible to download the stored acceleration data and also to transfer the data directly to a personal computer in real time. The former is called offline mode in this paper while the latter real-time mode. The power consumption of the accelerometers is sufficiently small. The sensor functions for about three weeks with three AA alkaline batteries in continuous-monitoring mode.

\section{Table 1 Specifications of the developed MEMS accelerometer}
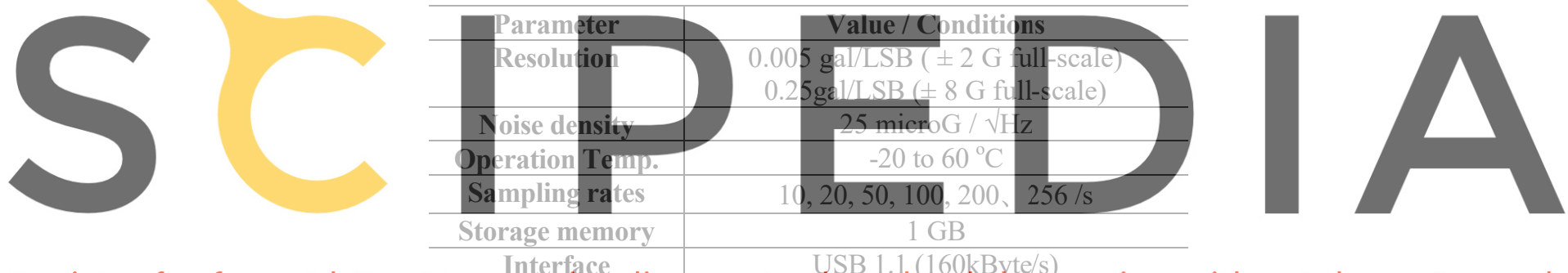

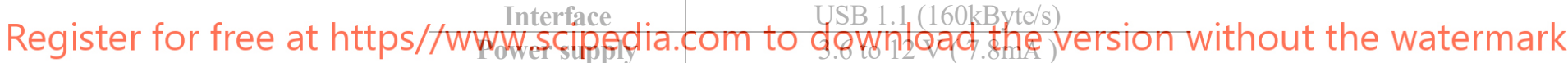

\begin{tabular}{c|c}
\hline Size & $69 \times 64 \times 16 \mathrm{~mm}$ \\
\hline Weight & $45 \mathrm{~g}$ \\
\hline
\end{tabular}

(a)
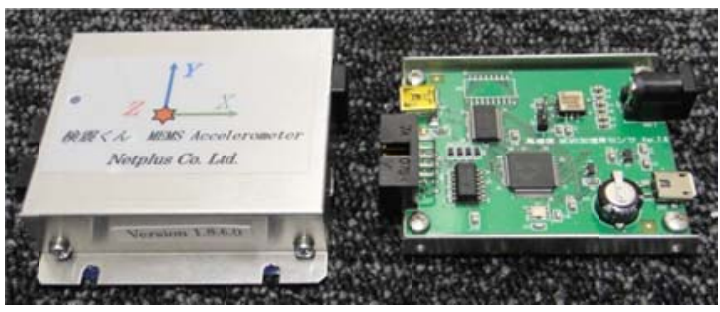

(b)

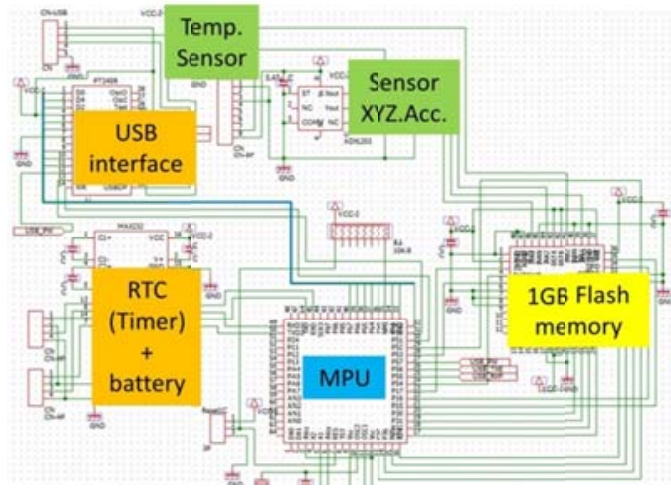

Figure 1: Developed accelerometer: (a) top view and (b) block diagram. 
The accelerometer has a 10-pin connector. Sensors are coupled by the connector, as it enables to operate multiple sensors and to supply power simultaneously. One accelerometer is assigned as a master and the others as slaves. The time is synchronised in accordance with the master. The acceleration data rate can be chosen among 10, 20, 50, 100, 200, 256 samples/second. It is noted that the rate of 256 samples/ second is available only in the realtime mode. The mode of data collection can be chosen between continuous monitoring and triggered monitoring. The continuous monitoring signifies MEMS record acceleration data in accordance with the predefined sample rate. In case of the continuous monitoring with 100 samples/ second, the 1-GB memory becomes full around in 22 days. The triggered monitoring collects acceleration data every second. However, in case the amplitude of the acceleration for each second is smaller than the specified offset value, only the average value or maximum and minimum values are stored. In case the amplitude is larger than the specified value, the data is stored according to the specified sample rate. The 1-GB memory can store data for one year at maximum with the trigger monitoring of 100 samples/ second in case the amplitude does not exceed the predefined offset values during the monitoring period. The accelerometers contain a RTC. Since the RTC does not output sub-second, the RTC time is read at the beginning, the middle, and the last of every second. When the displayed time of an accelerometer deviates from the RTC, it is corrected by $1 / 400$ second. The operation permits matching the displayed time to RTC without changing the number of samples per second.

The operation permits matching the displayed time to RTC without changing the number

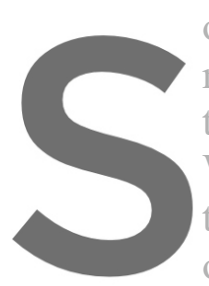
of samples per second match them with RT the beginning of the init When they receive the the RTC of plural acdelerometers are adjusted. of the slave acceleroneters is set to the RTC o
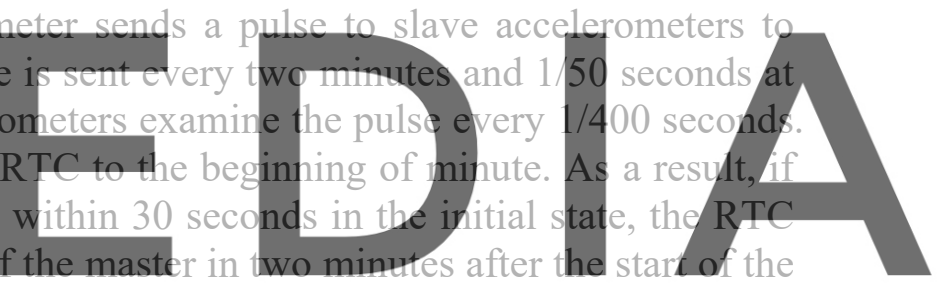

measurement. Since the displayed time of each accelerometer is matched to RTC, the

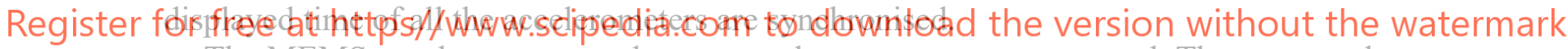

The MEMS accelerometers and servo accelerometers were compared. The compared servo accelerometers were capable of measuring $\pm 20 \mathrm{~m} / \mathrm{s}^{2}$. The noise density was $1 \mu \mathrm{G} / \sqrt{\mathrm{Hz}}$. A MEMS accelerometer and servo accelerometer were located on a floor. Arbitrary vibrations were given by hitting the floor by foot. The sampling rate of both accelerometers was set as 256 samples/ second. Figure 2 a shows vertical vibrations calibrated by the two accelerometers in the vertical direction. In the present paper, the $\mathrm{X}$ and $\mathrm{Y}$ axis denote horizontal vibrations while the $\mathrm{Z}$ axis vertical vibration. The vertical axis indicates the amplitude of the frequency component. It is noted that both accelerometers show the noise equal to about $1 / 2500 \mathrm{~g}$ in Figure $2 \mathrm{a}$ due to the lack of a low pass filter. Figure $2 \mathrm{~b}-\mathrm{d}$ present the comparison of frequency power spectra between MEMS accelerometer and servo accelerometers in $\mathrm{X}, \mathrm{Y}, \mathrm{Z}$ axis. The frequency power spectra were calculated as the level of vibrations $\left(L_{v}\right)$ according to the equation (1) 


$$
L_{v}=20 \log \frac{a}{a_{0}}(\mathrm{~dB})
$$

where:

$a$ is acceleration,

$a_{0}$ is equal to $10^{-5} \mathrm{~m} / \mathrm{s}^{2}$.

When the acceleration was over $30 \mathrm{~dB}$, both accelerometers showed good agreement especially in the $\mathrm{X}$ and $\mathrm{Z}$ axis (see, Figure $2 \mathrm{~b}, \mathrm{~d}$ ). On the other hand, the MEMS accelerometer showed different values from the servo accelerometer when the acceleration was over $30 \mathrm{~dB}$. However, the value $(30 \mathrm{~dB})$ is nearly equal to $3.1 / 10000 \mathrm{~g}$. It is a very small value compared to expected acceleration in heritage structures during health monitoring tests. Considering The tested MEMS accelerometers are much more cost efficient, light and robust than servo accelerometers, in spite of the dissimilarities of measurement results below $30 \mathrm{~dB}$, they are considered suitable for health monitoring tests of heritage structures.
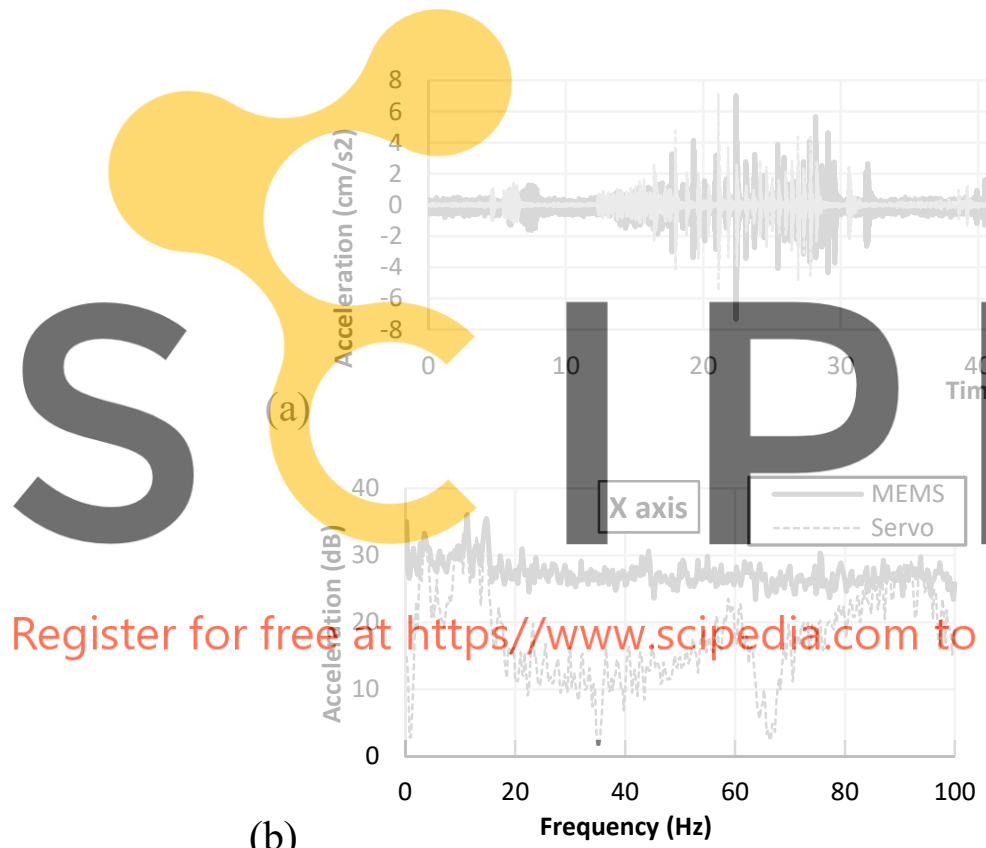

(b)

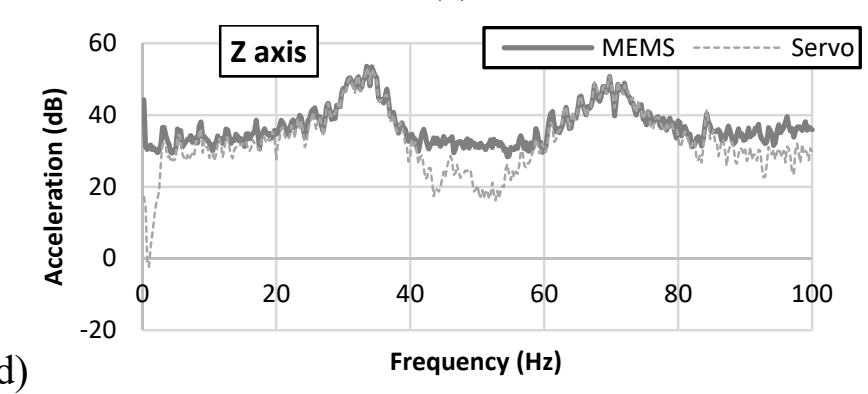

(d)
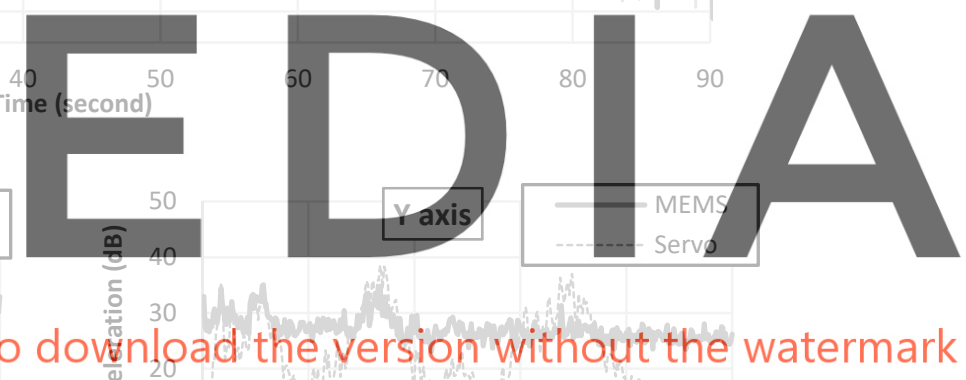

(c)

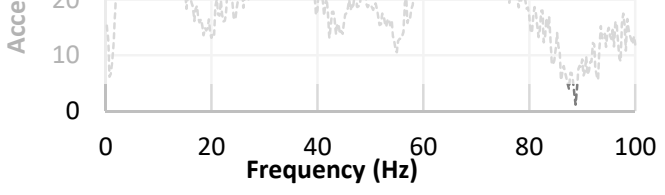

Figure 2: A comparison of the measurement results of MEMS accelerometer and servo accelerometer: (a) acceleration time history in the $\mathrm{Z}$ axis and (b-d) frequency power spectra in $\mathrm{X}, \mathrm{Y}, \mathrm{Z}$ axis. 


\section{HEALTH MONITORING TESTS}

\subsection{Description of the case study objectives}

The monitoring tests were performed on a two-tier pagoda and five-tier pagoda. The Pashupatinath temple is a two-tier pagoda located in the historic centre of Bhaktapur (Figure 3a). It is also known as Yaksheshvara Mahadev temple. It is a replica of the same name temple built in Bagmati, Kathmandu [5]. The original structure was built by King Yaksha Malla in the 15th century [6]. It was reconstructed twice: in 1692 and after an earthquake of 1934.

The Nyatapola temple is a five-tier pagoda situated in the Taumadh square, Bhaktapur (Figure 3b). The temple was constructed by King Bhupatindra Malla in 1702 [7]. The top tier was collapsed during the earthquake of 1934 and later it was reconstructed [6]. Minor repair was conducted in 1962 and the roofs were reconstructed between 1998 and 1999. It is one of the two surviving five-tier pagodas in the Kathmandu valley.
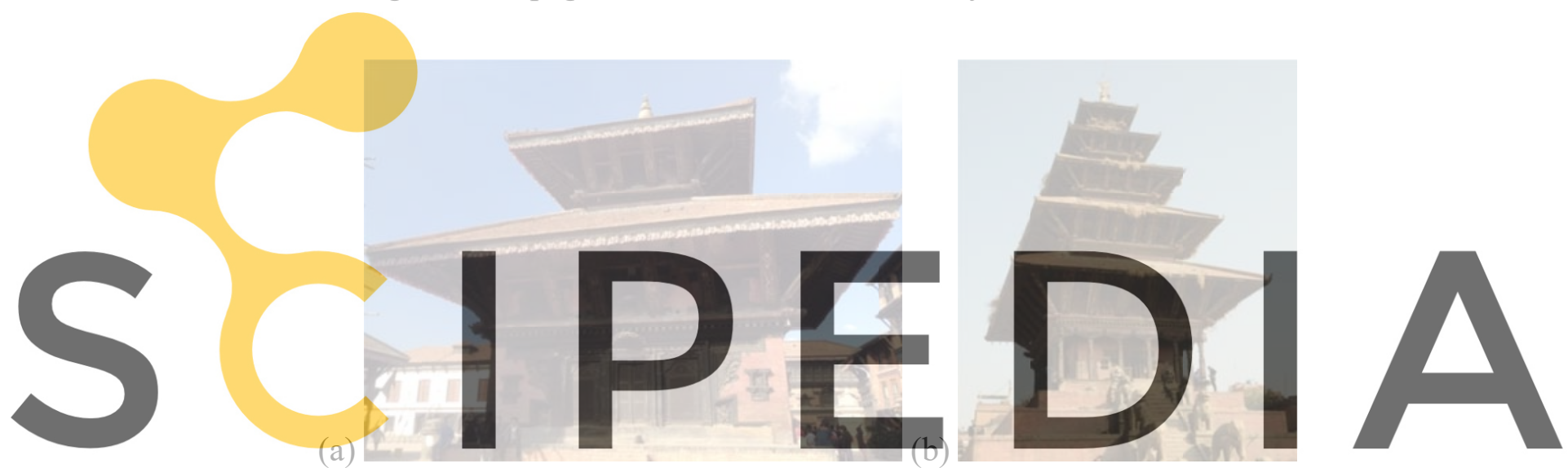

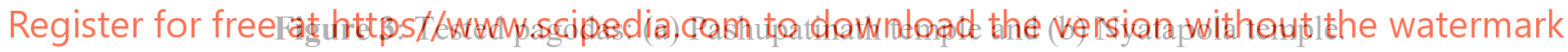

\subsection{Monitoring setup}

Three sensors (P1-3) were installed to the Pashupatinath temple as shown in Figure 4a. The P1 sensor was put on the plinth surface. Two sensors (P2-3) were put at the height of the ceiling level of the ground tier. The P2 sensor was attached to a pillar while the P3 to a wall. The two sensors were attached to a masonry wall. The triggered monitoring was applied. The trigger level was set as $1 / 1000 \mathrm{~g}$. In case the difference between the maximum and the minimum value within one second exceeded $1 / 1000 \mathrm{~g}$, the data was recorded at the rate of 100 samples/ second. In case the difference between the maximum and the minimum value was less than $1 / 1000 \mathrm{~g}$, only the maximum and minimum values were recorded. The monitoring was continued for three months (from December, 2016 to March, 2017).

Three MEMS accelerometers (N1-3) were installed to Nyatapola temple (Figure 4b). The N1 sensor was located at the plinth surface, the N2 sensor at the ceiling level of first tier, and the N3 sensor at the ceiling of the third tier. N2 and N3 sensors were attached to timber beams. The triggered monitoring was adopted. The trigger level was set as $1 / 1000 \mathrm{~g}$. The monitoring 
was continued for four months (from August, 2017 to December, 2017). Both tests were conducted in offline mode.

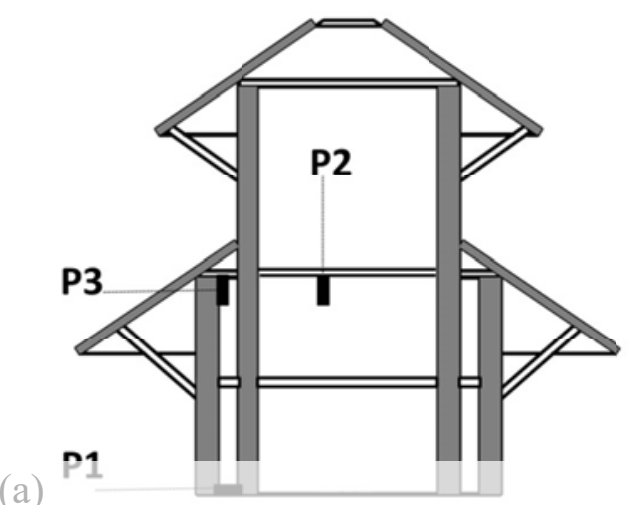

(b)

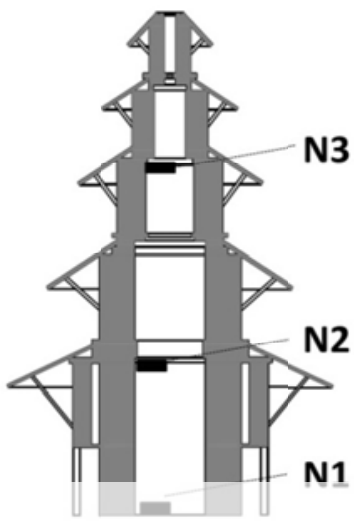

Figure 4: Sensor locations: (a) Pashupatinath temple and (b) Nyatapola temple.

\subsection{Results of monitoring}

Five earthquakes were detected by sensors during the monitoring period. In fact, number of earthquakes occurred around Nepal during the period but they were not captured by the sensors. This is presumably derived from the assigned trigger condition (1/1000g). The value was possibly too low for 2017. One of them, recorded waveforms per captured waveforms were decomposed by Fourier transforms (Figures 5). P2 sensor calibrated

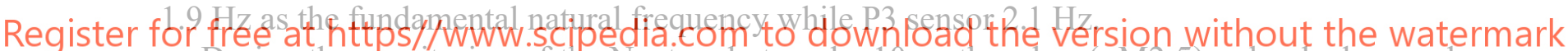
During the monitoring of the Nyatapola temple, 10 earthquakes (>M2.5) unleashed around

Nepal. Among them, two earthquakes were detected by the three sensors. They are a M4.5 earthquake on August 21, 2017 (named earthquake-A in this paper) and M5.0 earthquake on December 8, 2017 (earthquake-B) [8]. For the earthquake-A, N3 sensor recorded the maximum amplitude equal to $0.003 \mathrm{~g}$. As for the earthquake- $\mathrm{B}$, the $\mathrm{N} 3$ sensor recorded maximum amplitude close to $0.009 \mathrm{~g}$. From the earthquake- $\mathrm{A}$, a natural frequency equal to $1.60 \mathrm{~Hz}$ was detected and from the earthquake-B a natural frequency equal to $1.48 \mathrm{~Hz}$ (Figure 6 a-c). In fact a M6.9 earthquake hit Mainling, Tibet on November 18, 2017. The epicentre was about $1,000 \mathrm{~km}$ east of Bhaktapur. As for this earthquake, waveforms were recorded by $\mathrm{N} 2$ and N3 sensors although they did not permit estimation of natural frequencies of the pagoda due to the lack of sufficient amount of data. 


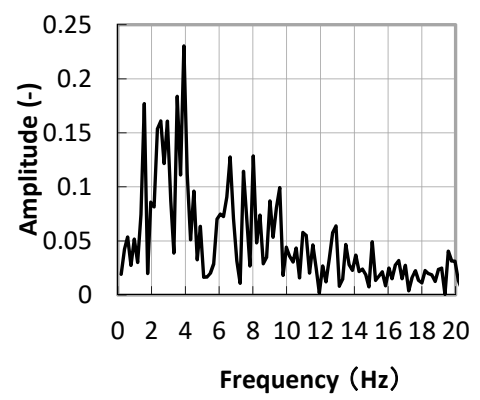

(a)

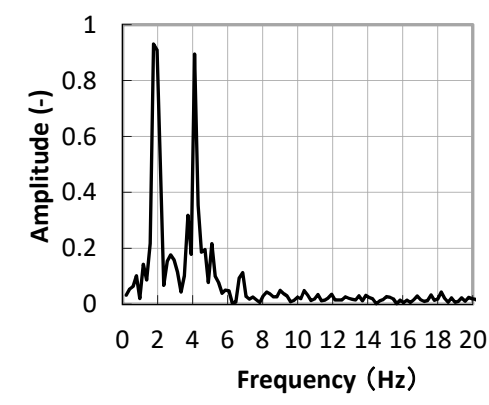

(b)

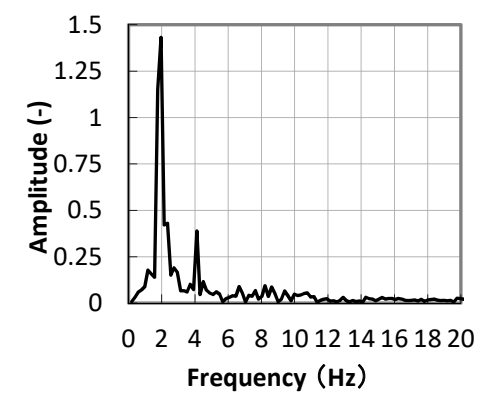

(c)

Figure 5: Fourier transforms in X axis of a M4.7 earthquake February 27, 2017, which hit Pashupatinath temple: (a) P1 sensor, (b) P2 sensor and (c) P3 sensor.
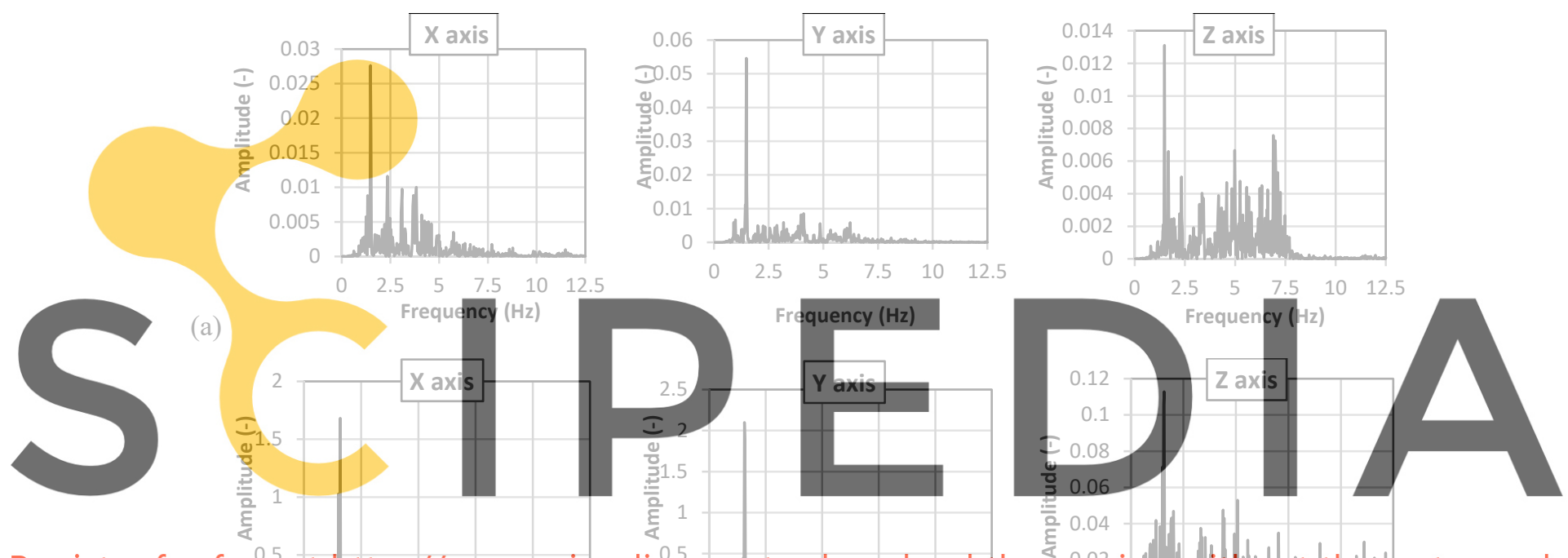

Register for free at https//www.scipedia.com to download the version without thelwatermark

(b)
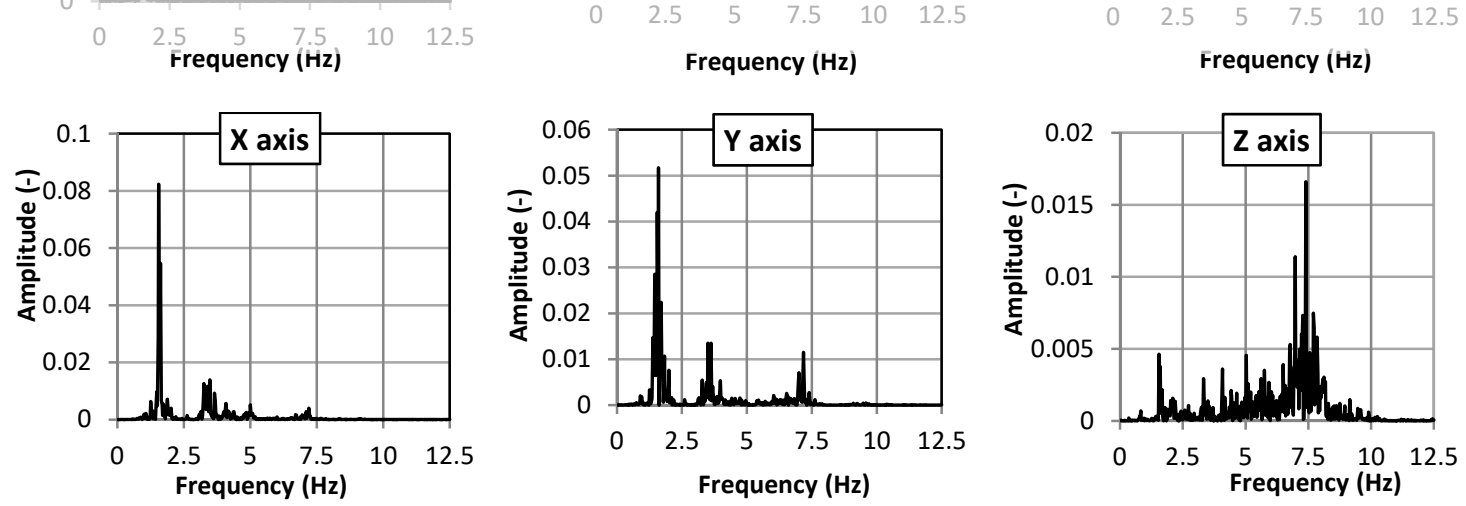

Figure 6: Fourier transforms of a M5.0 earthquake on December 8, 2017, which hit Nyatapola temple: (a) N1 sensor, (b) N2 sensor and (c) N3 sensor. 


\section{CONCLUSIONS}

The paper introduced newly developed MEMS accelerometers. Health monitoring tests were performed on two multi-tier pagodas. They measure acceleration tri-axially under the conditions set by an internal MPU. The noise level is less than $1 / 5000 \mathrm{~g}$ and to an inclination of 0.01 degree. They can be controlled by the trigger criterion. It allows the accelerometers to record detailed data of only strong vibrations, saving the battery and disk space. Theoretically, the monitoring for two years at maximum is possible without changing the battery or downloading/removing the stored data.

Health monitoring tests were performed on two multi-tier pagodas using the developed MEMS accelerometers. In both tests, the accelerometers detected multiple earthquakes, as it permitted estimation of the fundamental frequency. It is added that the used MEMS accelerometers are still under development. They will be improved in terms of data collection. Currently cable connections are necessary for the MEMS accelerometers to send data to a server PC. Using network connections, the MEMS will send data to a server PC.

Acknowledgements. The research is being supported by the funding of Grant-in-Aid for scientific research (A) provided by the Japan Society for the Promotion of the Science (Grant number: 16H01825). The authors show appreciation to Dr. Manjip Shakya for his assistance in conducting the laboratory tests at KHWOPA engineering college, Nepal.

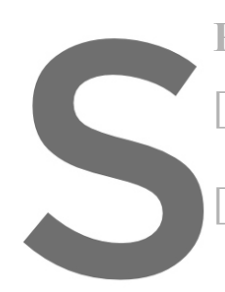

REFERENCES

[1] Tadigadapa,

perspectives." Meas

2] Sabato, A., Niezrecl

boards for structura

(2016): 226-235.
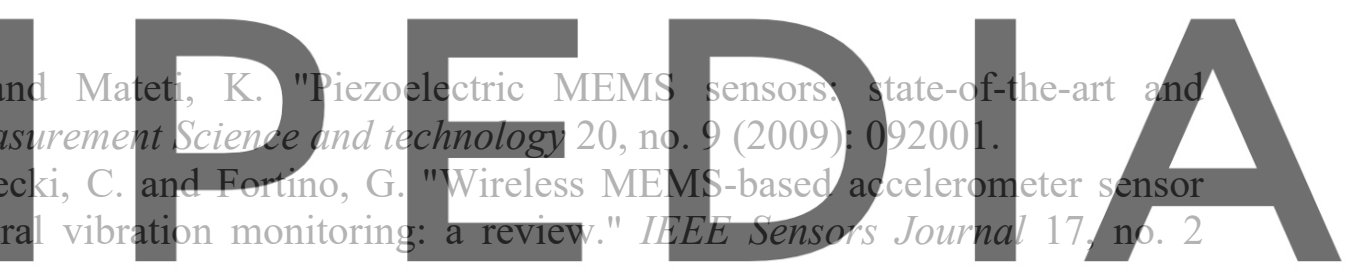

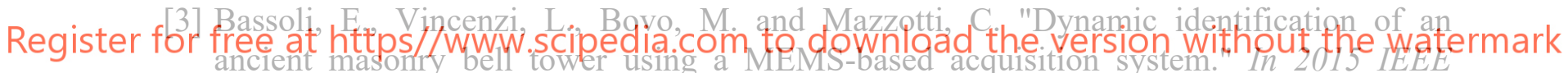
ancient masonry bell tower using a MeMs-based acquisition system. In 2015 Itet

Proceedings, pp. 226-231. IEEE, (2015).

[4] "Analog device Data Sheet ADXL354/ADXL355 (2018) ".

https://www.analog.com/media/en/technical-documentation/data-sheets/adx1354_355.pdf.

[5] Wiesner, U. Nepalese temple architecture: its characteristics and its relations to Indian development. Vol. 8. Brill, (1978).

[6] Amātya, S. Monument conservation in Nepal: My experience with the world heritage sites of Kathmandu valley. Vajra Publications, (2007).

[7] Shrestha, D.B. and Singh, C.E. The History of Ancient and Medieval Nepal in a Nutshell: With Some Comparative Traces of Foreign History. Vol. 1. (1972).

[8] USGS, " Earthquake hazards" (2019).

https://www.usgs.gov/natural-hazards/earthquake-hazards/earthquakes 